\title{
ARTICLE \\ Role of the medial prefrontal cortex in the effects of rapid acting antidepressants on decision-making biases in rodents
}

\author{
C. A. Hales ${ }^{1}$, J. M. Bartlett ${ }^{1}$, R. Arban ${ }^{2}$, B. Hengerer ${ }^{2}$ and E. S. J. Robinson ${ }^{1}$
}

\begin{abstract}
Major depressive disorder is a significant and costly cause of global disability. Until the discovery of the rapid acting antidepressant (RAAD) effects of ketamine, treatments were limited to drugs that have delayed clinical benefits. The mechanism of action of ketamine is currently unclear but one hypothesis is that it may involve neuropsychological effects mediated through modulation of affective biases (where cognitive processes such as learning and memory and decision-making are modified by emotional state). Previous work has shown that affective biases in a rodent decision-making task are differentially altered by ketamine, compared to conventional, delayed onset antidepressants. This study sought to further investigate these effects by comparing ketamine with other NMDA antagonists using this decision-making task. We also investigated the subtype selective GluN2B antagonist, CP-101,606 and muscarinic antagonist scopolamine which have both been shown to have RAAD effects. Both CP-101,606 and scopolamine induced similar positive biases in decision-making to ketamine, but the same effects were not seen with other NMDA antagonists.

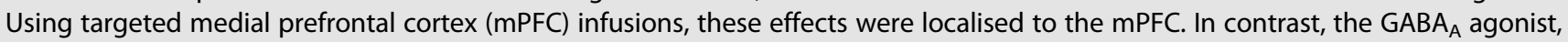
muscimol, induced general disruptions to behaviour. These data suggest that ketamine and other RAADs mediate a specific effect on affective bias which involves the MPFC. Non-ketamine NMDA antagonists lacked efficacy and we also found that temporary inactivation of the mPFC did not fully recapitulate the effects of ketamine, suggesting a specific mechanism.
\end{abstract}

Neuropsychopharmacology (2020) 45:2278-2288; https://doi.org/10.1038/s41386-020-00797-3

\section{INTRODUCTION}

Major depressive disorder (MDD) is a prevalent psychiatric disorder, affecting over 300 million people globally [1]. It is the leading worldwide cause of disability, and, until recently, pharmacological treatments were limited to drugs that take weeks to improve symptoms and subjective reporting of mood [2]. The discovery of the rapid acting antidepressant (RAAD) effects of ketamine, an NMDA receptor antagonist, has rejuvenated the field by demonstrating that subjective changes in mood in depressed patients can be seen less than $2 \mathrm{~h}$ following administration and are sustained for at least 7 days in some patients [3]. Although this RAAD has been shown repeatedly [4-8], the mechanism underlying this effect is unclear, and better understanding could be critical for the development of new, fastacting treatments.

Patients with MDD exhibit affective biases, whereby impairments in emotional processing leads to reduced positive and/or enhanced negative biases in multiple cognitive domains, including attention, memory, emotional interpretation and decisionmaking [9-11]. In humans, acute (and chronic) treatment with conventional antidepressants induces positive biases in emotional memory and recognition in healthy controls [12-14] and patients [15], despite a lack of subjectively reported change in mood. It has been suggested that similar affective biases can also be measured in non-human animals using learning and memory tasks [16] and in decision making under ambiguity (first demonstrated by Harding et al. [17] using a judgement bias task). For review and more detailed discussion of translational studies of affective biases see Robinson and Roiser [18]. Judgement bias tasks (also known as cognitive bias tasks, or ambiguous cue interpretation tasks) were first developed as a cognitive test to measure animal affect (see reviews by Mendl et al. [19] and Roelofs et al. [20]). In the task, animals are trained to associate the presentation of two distinct reference cues with two differently valenced outcomes (e,g. positive: reward/high reward, or negative/less positive: punishment/low reward). After training, individuals are presented with untrained, ambiguous cue(s), and responses to these are measured to see whether they respond with a positive or negative bias (more responses matching the positive or negative choice respectively). A recent systemic review and meta-analysis across judgement bias tasks in animals has shown that across 20 published research articles, pharmacological manipulations to induce changes in affective state overall did alter decision making about ambiguous cues as predicted [21], demonstrating the validity of these types of tasks. In previous work in rodents in our lab using a reward-based judgement bias task (first reported by Hales et al. [22]), decision making biases were differentially altered by conventional, delayed acting antidepressants versus the RAAD ketamine [24]. In this task, where reference cues are associated with more or less positive outcomes [22-24], we found that an acute, low dose of ketamine, but not acute treatment with another NMDA receptor antagonist, PCP, immediately induced more optimistic decision making, the direction that would be induced by a more positive affective state, whereas acute treatment with

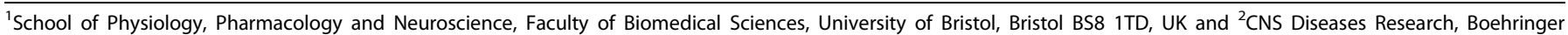
Ingelheim GmbH \& Co. KG, Biberach an der Riss, Germany

Correspondence: E. S. J. Robinson (emma.s.j.robinson@bristol.ac.uk)
}

Received: 21 January 2020 Revised: 1 July 2020 Accepted: 8 July 2020

Published online: 25 August 2020 
conventional antidepressants had no effect on bias [24]. However, when given chronically, the conventional antidepressant fluoxetine did induce a positive bias [24], but only over a timescale similar to the drugs' efficacy in patients, as measured by selfreported improvements in symptoms and mood [2]. The same pattern was also seen in this task with negative affective states, where a chronic stress manipulation, but not an acute stressor, induced more pessimistic decision making at later time points [22].

The aim of this study was to build upon these findings by testing a selection of other drugs that act via NMDA receptor antagonism: lanicemine, a low-trapping NMDA receptor channel blocker developed for the treatment of MDD, but failed to show efficacy in clinical trials [25]; memantine, an Alzheimer's medication that is a moderate affinity, non-competitive NMDA receptor antagonist, but also lacked antidepressant efficacy in clinical trials $[5,26]$; and MK-801, a potent, non-competitive NMDA receptor antagonist that has shown RAAD efficacy in animal models [27]. We also tested other compounds that have been shown to have RAAD in human clinical trials: the GluN2B subunit selective NMDA receptor antagonist CP-101,606 [28], and the acetylcholine muscarinic receptor antagonist scopolamine [29]. We also tested additional doses of ketamine and PCP to ensure we had examined effects across a wider range of receptor occupancy and in line with doses commonly used in preclinical animal models used to study depression [30]. To investigate the mechanism underlying the rapid positive change in decision-making bias we tested local administration of drugs shown to cause this effect directly into the prefrontal cortex (PFC), a brain area thought to be critical in the mechanism of RAAD of ketamine [31, 32] and previously shown to modulate learning biases in rodents [33].

\section{MATERIALS AND METHODS}

Animals and apparatus

Three cohorts of male Lister Hooded rats (each cohort $n=16$ ) were used (Envigo, UK). Rats were pair-housed with environmental enrichment, consisting of a red $3 \mathrm{~mm}$ Perspex house $(30 \times 10 \times$ $17 \mathrm{~cm})$, a large cardboard tube $(10 \mathrm{~cm}$ diameter), a wood chew block $(9 \times 2.5 \times 2.5 \mathrm{~cm})$ and a rope tied across the cage lid (the rope was not present in cages for cohort 3 post-surgery to avoid any possibility of implanted cannula getting caught). Animals were kept under temperature $\left(19-23^{\circ} \mathrm{C}\right)$ and humidity $(45-65 \%)$ controlled conditions on a 12-h reverse lighting cycle (lights off at 08:00 h). Water was available ad libitum in the home cage, but rats were maintained at no less than $90 \%$ of their free-feeding body weight, matched to a standard growth curve, by restricting access to laboratory chow (LabDiet, PMI Nutrition International) to $\sim 18 \mathrm{~g}$ per rat per day. All procedures were carried out under local institutional guidelines (University of Bristol Animal Welfare and Ethical Review Board) and in accordance with the UK Animals (Scientific Procedures) Act 1986. Rats weighed 270-305 g (cohort 1)/250-295 g (cohort 2)/240-290 g (cohort 3) at the start of training, and 400-465 g (cohort 1)/360-460 g (cohort 2)/320-380 g (cohort 3 ) by the start of experimental manipulations. During experiments all efforts were made to minimise suffering including using a low-stress method of drug administration [34], and at the end of experiments rats were killed by giving an overdose of sodium pentobarbitone $(200 \mathrm{mg} / \mathrm{kg})$. Behavioural testing was carried out between 0800 and $1800 \mathrm{~h}$, using standard rat operant chambers (Med Associates, Sandown Scientific, UK) as previously described $[22,24]$. Operant chambers $(30.5 \times 24.1 \times 21.0 \mathrm{~cm})$ used for behavioural testing were housed inside a light-resistant and sound-attenuating box. They were equipped with two retractable response levers positioned on each side of the centrally located food magazine. The magazine had a house light ( $28 \mathrm{~V}, 100 \mathrm{~mA})$ located above it. An audio generator (ANL-926, Med Associates, Sandown Scientific, UK) produced tones that were delivered to each chamber via a speaker positioned above the left lever. Operant chambers and audio generators were controlled using KLimbic software (Conclusive Solutions Ltd., UK).

\section{Judgement bias training}

Animals were trained and tested using a high versus low reward version of the judgement bias task as previously reported [22, 24]. Rats were first trained to associate one tone $(2 \mathrm{kHz}$ at $83 \mathrm{~dB}$, designated high reward) with a high value reward (four $45 \mathrm{mg}$ reward pellets; TestDiet, Sandown Scientific, UK) and the other tone $(8 \mathrm{kHz}$ at $66 \mathrm{~dB}$, designated low reward) with a low value reward (one $45 \mathrm{mg}$ reward pellet) if they pressed the associated lever (either left or right, counterbalanced across rats) during the $20 \mathrm{~s}$ tone (see Fig. 1 for a detailed depiction of the task). Unless otherwise specified in Table S1, response levers were extended at the beginning of every session and remained extended for the duration of the session (maximum $1 \mathrm{~h}$ for all session types). All trials were self-initiated via a head entry into the magazine, followed by an intertrial interval (ITI), and then presentation of the tone. Pressing the incorrect lever during a tone was punished by a $10 \mathrm{~s}$ timeout, as was an omission if the rat failed to press any lever during the $20 \mathrm{~s}$ tone. Lever presses during the ITI were punished by a $10 \mathrm{~s}$ timeout. During a timeout, the house light was illuminated, and responses made on levers were recorded but had no programmed consequences.

Animals underwent a graduated training, and were required to meet criteria for at least two consecutive days before progressing to the next stage. Training stages were as follows:

(1) Magazine training: tone played for $20 \mathrm{~s}$ followed by release of one pellet into magazine. Criteria:.20 pellets eaten for each tone frequency.

(2) Tone training: response on lever during tone rewarded with one pellet. Only one tone frequency, and one lever available per session. Criteria: $>50$ trials completed.

(3) Discrimination training: response on correct corresponding lever only during tone rewarded with one pellet. Both tones played (pseudorandomly) and both levers available. Criteria: $>70 \%$ accuracy for both tones, $<1: 1$ ratio of correct: premature responses and no significant difference on any behavioural measures analysed over three sessions.

(4) Reward magnitude training: As for discrimination training but $2 \mathrm{kHz}$ tone now rewarded with four pellets, $8 \mathrm{kHz}$ tone rewarded with one pellet. Criteria: as for discrimination training but with $>60 \%$ accuracy for both tones.

All training sessions consisted of a maximum of 100 trials. Table S1 contains full details of training stages and criteria used. Rats were considered trained when they maintained stable responding for three consecutive days. This was after a maximum of 29 sessions for cohort 1, 25 sessions for cohort 2, and 25 sessions for cohort 3 (see Table S1 for details of session numbers for each training stage).

\section{Judgement bias testing}

Baseline sessions (100 trials: 50 high and 50 low reward tones; presented pseudorandomly, for details see Table S1) were conducted on Monday and Thursday. Probe test sessions (120 trials: 40 high reward, 40 low reward, and 40 ambiguous midpoint tones that were $5 \mathrm{kHz}$ at $75 \mathrm{~dB}$; pseudorandomly, for details see Table S1) were conducted on Tuesday and Friday. The midpoint tone was randomly reinforced whereby $50 \%$ of trials had outcomes as for the high reward tone, and $50 \%$ had outcomes as for the low reward tone. This was to ensure a specific outcome could not be learnt, and to maintain responding throughout the experiments (see Fig. 1 and Table S1 for a detailed description of how this was implemented). Cohort 1 were used to test the effect of acute systemic treatments with putative RAAD and other NMDA 

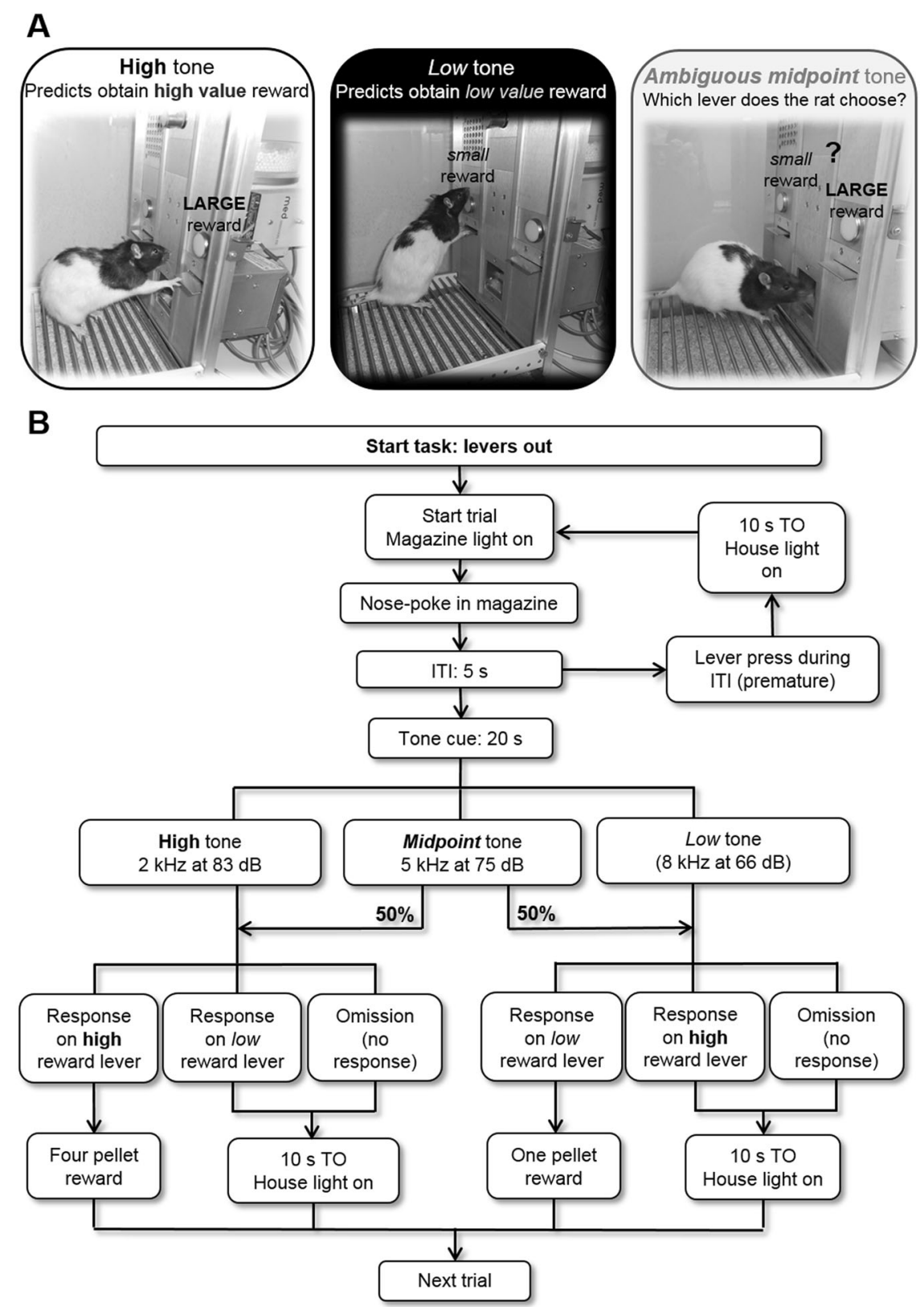

Fig. 1 Schematic of the judgement bias task and trial structure. In the judgement bias task (JBT), rats are trained to associate one tone frequency $(2 \mathrm{kHz})$ with a high value reward: i.e. if the rat presses the correct lever (shown as the left lever in (a), but counterbalanced across rats in a cohort) they receive a high value reward (four reward pellets). They also learn to associate a second tone frequency ( $8 \mathrm{kHz}$ ) with receiving a low value reward (one reward pellet; shown in (a) as pressing the right lever during the tone). Judgement bias, or decision making about an ambiguous cue, which is known to be influenced by affective state, can be probed by presenting an ambiguous tone that has a mipdoint frequency between the two reference cues $(5 \mathrm{kHz})$, and recording which lever the rat presses. If the rat is expecting the more positive outcome (indicative of an optimistic judgement bias), then they will more often choose the large reward lever, but if the rat is in a more negative affective state, they will expect the less positive outcome and more often choose the low reward lever, a pessimistic judgement bias. During the task, tones are presented within discrete trials, the format of which is depicted as a flow chart in (b). The task is self-initiated, and so each trial begins only once the rat makes a nosepoke entry into the magazine port. This is followed by a $5 \mathrm{~s}$ intertrial interval (ITI), during which time the rat has to wait and refrain from making a lever press response. If the rat does press a lever, they are punished with a 10 second timeout (TO). The tone cue is presented for a maximum of 20 seconds following the ITI, or until the rat makes a lever press response. The outcome following each lever press depends on which tone was played, and which lever was pressed. Correct lever presses to either reference tone (high or low tones) results in the corresponding reward being delivered to the magazine, whilst incorrect lever presses result in a $10 \mathrm{~s}$ TO. This TO also occurs if the rat fails to make any lever press during the $20 \mathrm{~s}$ tone presentation (an omission). During TOs, lever presses and magazine entries are recorded but have no consequences, meaning the rat has to wait to be able to begin the next trial. When the midpoint tone is presented, $50 \%$ of the time this tone is "classified" by the software as having the same response properties as the high reward tone. l.e., if the rat makes a high reward lever press during a midpoint tone presentation classified in this way, then they will receive a four pellet reward, but will experience the 10 s TO if they make a low reward lever press. Similarly, if the midpoint tone is "classified" as having the same response properties as the low reward tone, then a high reward lever press would result in a TO, whilst a low reward lever press would result in delivery of the small reward. In this way, each lever is only associated with the same reward outcome (i.e. four pellets for the high reward lever), but the midpoint tone becomes randomly reinforced, and so rats will maintain responding for this tone across multiple trials within a session, whilst being unable to learn a specific reward contingency to associate with the midpoint tone. 
receptor antagonists. Cohort 2 were made up of two groups of eight rats that had previously been used as control animals in another experiment (data not shown) and were then used for the extension of doses of ketamine and PCP. Cohort 3 were used for mPFC infusion experiments. For further details of the different treatments received by each cohort see Table S2.

Study 1: the effect of acute, systemic treatments with RAADs and NMDA receptor antagonists on judgement bias

Experimental design: Each study used a within-subject fully counterbalanced drug treatment schedule (see Table S2 for details of individual treatments). The study design followed the same procedures as used in our earlier work characterising the effects of ketamine in the JBT [24]. We also included a replication study with systemic ketamine in our infusion cohort in order to confirm similar systemic effects before proceeding to the infusion studies. Each animal received all doses for any given treatment in a counterbalanced design with drug doses separated by a minimum of $72 \mathrm{~h}$ and at least a 1 -week drug free period between different treatments. There is the potential for compensatory changes to develop due to repeated testing and the drug treatments, but these are minimised by managing washout periods and also recording and analysing the animals' baseline data in between drug studies. We are aware of the increasing evidence that ketamine, and potentially the other treatments tested, can have long lasting effects [35] which may not fully reverse over this dosing schedule. The counterbalanced design does mitigate the risks of any bias of these schedules on the results but there may be carryover effects which could influence the main findings. We carry out analysis of the between treatment baseline sessions (data shown in Table S3-S6) and these analyses do not suggest that the behavioural parameters we measure were affected for any of the cohorts over time. All drugs were given by intraperitoneal injection using a low-stress, non-restrained technique [34]. Ketamine ${ }^{*}$ (Sigma-Aldrich, UK), scopolamine $^{\S}$ (Tocris, UK), lanicemine ${ }^{¥}$ (Sigma Aldrich, UK), memantine ${ }^{¥}$ (Tocris, UK), MK- $801^{\S}$ (Tocris, UK) and PCP ${ }^{¥}$ (Sigma Aldrich, UK) were dissolved in $0.9 \%$ sterile saline and given $30^{\S}$ or $60^{*}$ minutes prior to testing. CP-101,606 (Experiment 1: Sigma Aldrich, UK; Experiment 2: Boehringer Ingelheim $\mathrm{GmbH}$ ) was dissolved in 5\% DMSO, $10 \%$ cremaphor and $85 \%$ sterile saline and given $60 \mathrm{~min}$ prior to testing. Drug doses were selected based on previous rodent behavioural studies [24, 36]. Doses for ketamine and PCP were chosen to extend the range of doses tested in this task e.g. higher doses of ketamine and lower doses of PCP were used than previously [24]. For all studies, the experimenter was blind to drug dose. The order of testing for each cohort is displayed in Table S2.

\section{Study 2: mPFC cannulation and infusions}

mPFC cannulation: To localise the site and mechanism of action of RAAD drugs, rats were implanted with mPFC guide cannula. Rats were anesthetised with isoflurane/O2 and secured in a stereotaxic frame. Bilateral 32-gauge guide cannulae (Plastics One, UK) were implanted in the mPFC according to the stereotaxic coordinates: anteroposterior $+2.7 \mathrm{~mm}$, lateral $\pm 0.75 \mathrm{~mm}$ and dorsoventral $-2.0 \mathrm{~mm}$ from bregma [37]. The cannulae were secured to the skull with gentamicin bone cement (DePuy CMW, UK) and stainless steel screws (Plastics One, UK). Animals received long acting local anaesthetic during surgery, and after surgery the animals were housed individually for $2-3 \mathrm{~h}$ then allowed 10-13 days recovery in normal paired housing conditions. Following the recovery period, rats underwent 1 week of baseline sessions to re-establish performance. Following this, 1 week of probe testing was carried out to check that judgement of the ambiguous tone had not altered after surgery. Based on this, another 2 weeks of probe testing (4 test sessions) was then conducted.
Systemic ketamine: Following this, an acute systemic treatment with ketamine was given as a positive control manipulation to ensure that bias could still be manipulated post-surgery. This study was a within-subject fully counterbalanced design, with two treatments (see Table S2, top row of section 3), with the experimenter blind to drug dose. Ketamine $(1.0 \mathrm{mg} / \mathrm{kg}$, Sigma Aldrich, UK) was dissolved in $0.9 \%$ sterile saline vehicle $(0.0 \mathrm{mg} / \mathrm{kg})$ and was given by intraperitoneal injection using a low-stress, nonrestrained technique [34] $60 \mathrm{~min}$ prior to testing.

Infusion procedure: Rats were then used for mPFC infusion experiments. Rats were habituated to the infusion procedure during one session where animals were lightly restrained and the cannula dummy removed and then replaced. In a second habituation session animals were gently restrained while the cannula dummy was removed and a 33-gauge bilateral injector extending $2.5 \mathrm{~mm}$ beyond the length of the guide cannula was inserted into the mPFC. This was left in place for $2 \mathrm{~min}$, but no infusion occurred. During experimental infusions, the rats were gently restrained while the cannula dummy was removed and the injector inserted. The injector was left in place for $1 \mathrm{~min}$ prior to infusions of vehicle or drug $(1.0 \mu \mathrm{l}$ total volume) over $2 \mathrm{~min}$. The injector was left in place for a further $2 \mathrm{~min}$ to allow diffusion of the drug into the tissue surrounding the injector, and then the injector was removed and the dummy replaced. The ambiguous probe test session occurred $5 \mathrm{~min}$ after the dummy was replaced.

Infusion experiments: In the first infusion experiment vehicle (sterile phosphate-buffered saline (PBS); $0.0 \mu \mathrm{g} / \mu \mathrm{l})$, ketamine $(1.0 \mu \mathrm{g} / \mu \mathrm{l})$, muscimol $(0.1 \mu \mathrm{g} / \mu \mathrm{l})$ or scopolamine $(0.1 \mu \mathrm{g} / \mu \mathrm{l})$, all dissolved in sterile PBS, were infused intracerebrally into mPFC $5 \mathrm{~min}$ before testing. Following this, CP-101,606 $(1.0 \mu \mathrm{g} / \mu \mathrm{l}$ in the first study, $3.0 \mu \mathrm{g} / \mu \mathrm{l}$ in the second study) was dissolved in 10\% 2-hydroxypropyl-cyclodextrin and 90\% PBS and tested. All experiments used a within-subject fully counterbalanced design for drug treatments, with the experimenter blind to treatment. Drug doses were chosen based on the results from acute, systemic treatments (see Table S2).

Histology: Following the completion of mPFC infusions, rats were killed and brains were fixed and processed for histology. Rats were anesthetised with a lethal dose of sodium pentobarbitone ( $0.5 \mathrm{ml}$ Euthatal, $200 \mathrm{mg} / \mathrm{ml}$, Genus Express, UK) and perfused via the left ventricle with $0.01 \mathrm{M}$ PBS followed by $4 \%$ paraformaldehyde (PFA). The brains were removed and post-fixed in 4\% PFA for $24 \mathrm{~h}$. Prior to being cut, brains were transferred to $30 \%$ sucrose in $0.1 \mathrm{M}$ PBS and left for 2 days until brains were no longer floating. Coronal sections were cut at $40 \mu \mathrm{m}$ on a freezing microtome and stained with Cresyl Violet. Locations of the injector tip positions in the $\mathrm{mPFC}$ were mapped onto standardised coronal sections of a rat brain stereotaxic atlas [37] (Fig. 3).

Data and statistical analysis

Sample size was estimated based on our previous studies using the JBT $[22,24]$ but with a more conservative effect size as we were looking at acute rather than chronic effects and expected to see greater variation in mPFC infusion studies. Changes in judgement bias should occur without effects on other variables and therefore strict inclusion criteria were established to reduce any potential confound in the data analysis. Only animals which maintained more than $60 \%$ accuracy for each reference tone, and less than $50 \%$ omissions were used for analysis.

Cognitive bias index (CBI) was used as a measure of judgement bias in response to the midpoint tone. $\mathrm{CBI}$ was calculated by subtracting the proportion of responses made on the low reward lever from the proportion of responses made on the high reward lever. This created a score between -1 and 1 , where negative values represent a negative bias and positive values a positive 

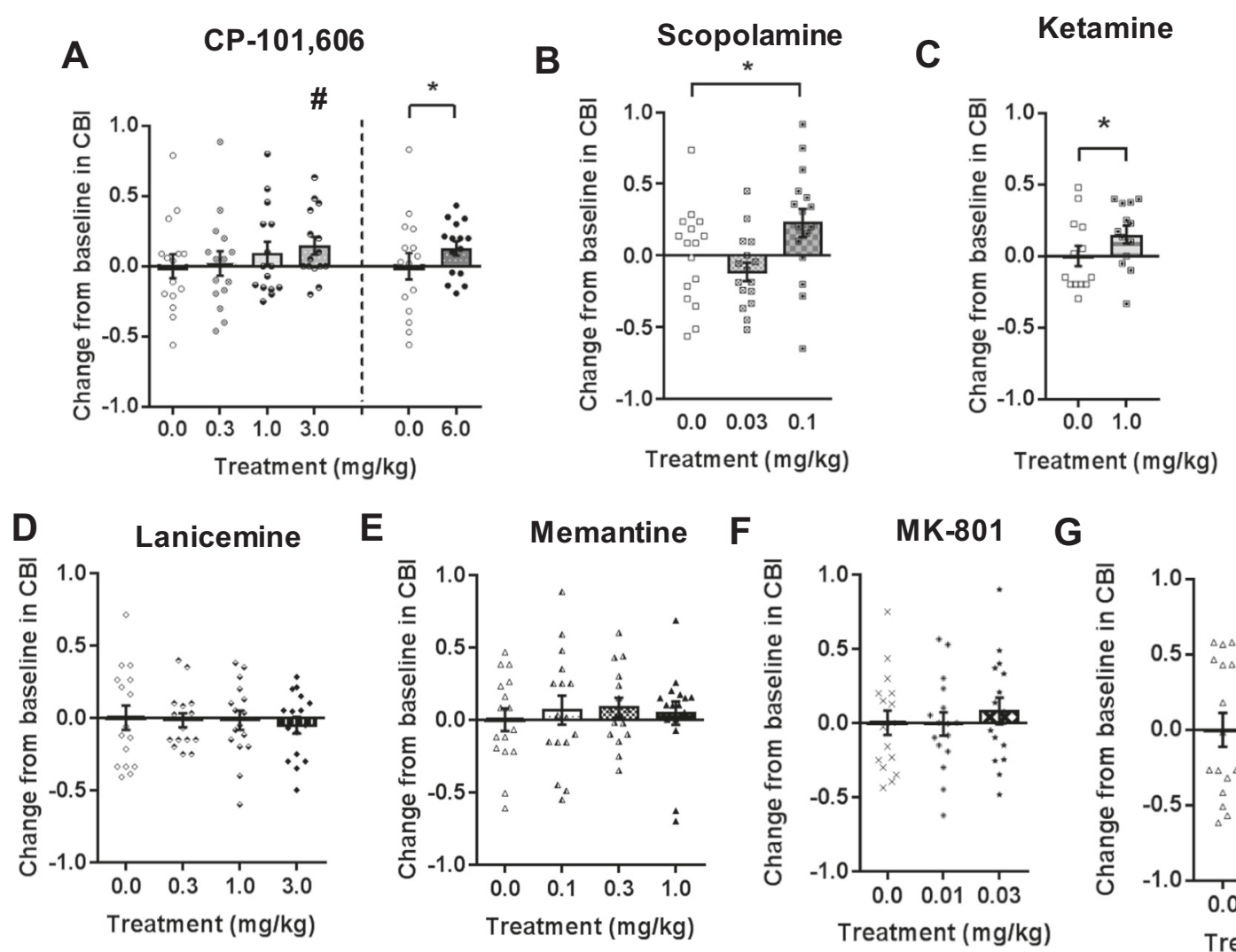

G

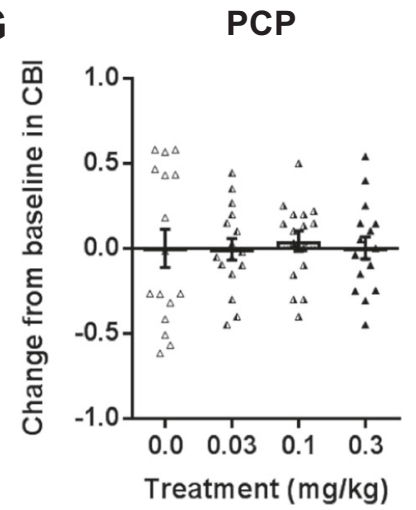

Fig. 2 The effect of acute treatment with rapid acting antidepressant drugs and NMDA receptor antagonists on judgement bias of the midpoint ambiguous tone. Ketamine $(0.0,1.0 \mathrm{mg} / \mathrm{kg} ; n=13)$, scopolamine $(0.0,0.03,0.1 \mathrm{mg} / \mathrm{kg} ; n=16), \mathrm{CP}-101,606(\mathrm{Expt} 1: 0.0,0.3,1.0$, $3.0 \mathrm{mg} / \mathrm{kg}, n=15 ;$ Expt 2: $0.0,6.0 \mathrm{mg} / \mathrm{kg}, n=15)$, lanicemine (0.0, $0.3,1.0,3.0 \mathrm{mg} / \mathrm{kg} ; n=16)$, memantine $(0.0,0.1,0.3,1.0 \mathrm{mg} / \mathrm{kg} ; n=16)$ and MK-801 (0.0, 0.01, $0.03 \mathrm{mg} / \mathrm{kg} ; n=16$ were administered acutely by intraperitoneal injection prior to testing on the judgement bias task. (a) Replicating previous studies, ketamine $(1.0 \mathrm{mg} / \mathrm{kg})$ positively changed CBI. (b) Scopolamine $(0.1 \mathrm{mg} / \mathrm{kg})$ also caused a positive change from baseline in CBI. (c) In experiment 1, there was no overall effect of CP-101,606 on change in CBI. A positive change was seen in experiment 2 with a higher $6.0 \mathrm{mg} / \mathrm{kg}$ dose. $\mathbf{d}-\mathbf{g}$ Lanicemine, memantine, MK-801 and low doses of PCP did not induce a change in CBI for the midpoint tone at the doses tested. Data shown and represent mean \pm SEM (bars and error bars) overlaid with individual data points for each rat. Dashed line (panel c) indicates separate, counterbalanced experiments. ${ }^{*} p<0.05$; ${ }^{\#} p<0.05$ for a one-sample $t$ test for $3.0 \mathrm{mg} / \mathrm{kg}$ CP-101,6060 only (comparison to a test value of zero representing a change in CBI for that drug only from baseline). CP-101,606, ketamine, lanicemine, memantine, PCP: 60 min pre-treatment; scopolamine, MK-801: 30 min pre-treatment.

bias. Change from baseline in $\mathrm{CBI}$ was then calculated for all experimental manipulations as follows: vehicle $(0.0 \mathrm{mg} / \mathrm{kg})$ probe test $\mathrm{CBI}$-drug dose probe test $\mathrm{CBI}$. This was calculated to take into account individual differences in baseline bias, and to make directional changes caused by drug treatments clearer. To provide a value for vehicle probe test sessions for this measure, the population average for the vehicle $(0.0 \mathrm{mg} / \mathrm{kg})$ probe test was taken away from each individual rats' $\mathrm{CBI}$ score for this dose. This allowed this measure to be analysed with repeated measures analysis of variance (rmANOVA) with drug dose as the withinsubjects factor for drug studies with more than two treatments, or paired samples t-test for studies with only two treatments. The raw data for $\mathrm{CBI}$ are included for all drug treatments in Fig. S1-S2.

Response latency, accuracy, omissions and premature responses were also analysed (see Table S8 for details of these). These measures were analysed with rmANOVAs with drug dose and tone as the within-subjects factors. Paired $t$ tests were performed as post-hoc tests if significant effects were established. Huynh-Feldt corrections were used to adjust for violations of the sphericity assumption, and Sidak correction was applied for multiple comparisons. All statistical tests were conducted using SPSS 24.0.0.2 for Windows (IBM SPSS Statistics) with $a=0.05$. Results are reported with the ANOVA F-value (degrees of freedom, error) and $p$-value as well as any post-hoc $p$-values. All graphs were made using Graphpad Prism 7.04 for Windows (Graphpad Software, USA).

\section{RESULTS}

Study 1: The effect of acute, systemic treatment with RAADs and selected NMDA receptor antagonists

$C P-101,606$. One animal was excluded in experiments 1 and 2 as accuracy criteria was not met on the vehicle drug dose. In the initial dose response study, CP-101,606 treated animals did not overall show any change in $\mathrm{CBI}$ (no main effect of drug dose $\left(F_{2.237,31.323}=0.811, p=0.495\right)$. Due to the possibility that there might be small change in $C B I$ for the highest dose $(3.0 \mathrm{mg} / \mathrm{kg}$; visual inspection of the data and one sample t-test (not corrected for multiple comparisons): $p=0.038$; Fig. $2 \mathrm{a}$ ), we then tested a higher dose of CP-101,606 $(6.0 \mathrm{mg} / \mathrm{kg})$ in the second experiment. This dose $(6.0 \mathrm{mg} / \mathrm{kg})$ resulted in a positive bias relative to vehicle treatment (paired samples $t$ test: $p=0.027$; Fig. 2a). In experiment $1,3.0 \mathrm{mg} / \mathrm{kg}$ CP-101,606 also caused a decrease in response latency (main effect of drug dose: $F_{3,42}=4.858, p=0.005$, posthoc: $p=0.027$; Table S7). There were no effects on other behavioural measures in experiment 1 (Table S7). In experiment 2, CP-101,606 $(6.0 \mathrm{mg} / \mathrm{kg})$ caused response latencies to decrease (main effect of drug dose: $F_{1,14}=27.396, p<0.001$; Table S7). This 
A

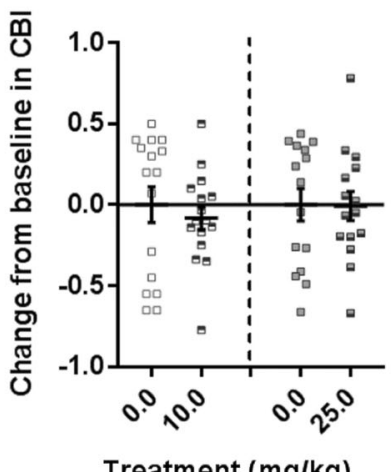

B

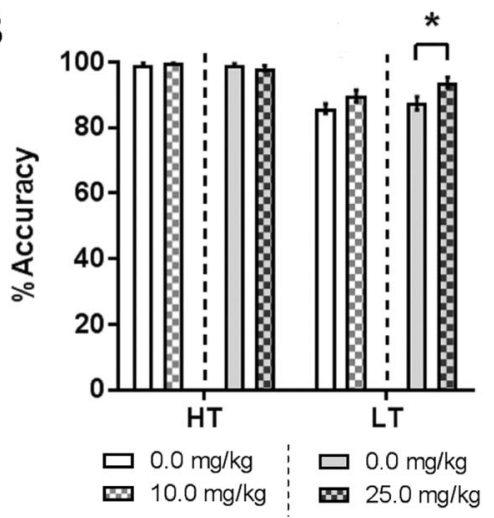

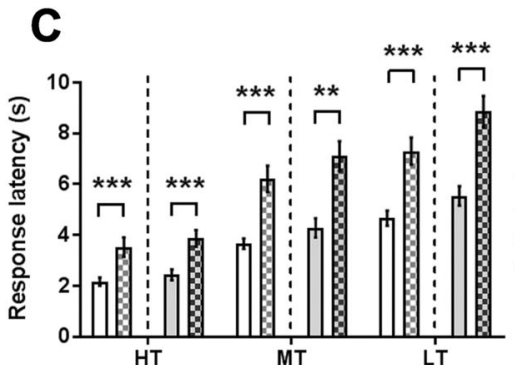

D

$\mathbf{E}$
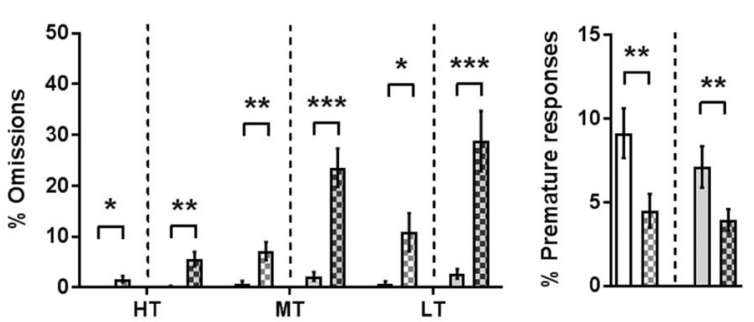

Fig. 3 Behavioural data from the judgement bias task following acute treatment with high doses of ketamine. Acute doses of ketamine (Expt 1: $0.0,10.0 \mathrm{mg} / \mathrm{kg}, n=16$; Expt 2: $0.0,25.0 \mathrm{mg} / \mathrm{kg}, n=16$ ) were administered by intraperitoneal injection to measure their effect on judgement bias. (a) Neither high dose of ketamine caused a change in interpretation of the midpoint tone. b Both doses of ketamine increased accuracy for the low tone. (c) Both doses of ketamine increased response latencies across all three tones. d Omissions were increased across all three tones following both ketamine doses. (e) High doses of ketamine $(10.0,25.0 \mathrm{mg} / \mathrm{kg})$ decreased premature responding. ${ }^{* * *} p<0.001,{ }^{* *} p<0.01,{ }^{*} p<0.05$. Data represent mean \pm SEM (panels b-e) with individual data points overlaid for each rat (panel a). Dashed lines indicate separate, counterbalanced experiments. 60 min pre-treatment. HT: high reward tone, MT: midpoint tone, LT: low reward tone.

dose had no effect on accuracy for the reference tones (Table S7), but did increase premature responses (paired samples $t$ test: $p=$ 0.001 ), and reduced omissions (main effect of drug dose: $F_{1,14}=$ 10.506, $p=0.006$; Table S7).

Scopolamine. The highest dose tested $(0.3 \mathrm{mg} / \mathrm{kg})$ had to be excluded from the analysis as most rats did not complete sufficient trials. Scopolamine $(0.1 \mathrm{mg} / \mathrm{kg})$ induced a positive bias (main effect of drug dose: $F_{2,30}=6.739, p=0.004$, post-hoc: $p=$ 0.035 ; Fig. 2b). This dose of scopolamine $(0.1 \mathrm{mg} / \mathrm{kg})$ also increased response latencies (main effect of drug dose: $F_{2,30}=$ 17.263, $p<0.001$, post-hoc: $p=0.001$; Table S7), increased premature responding (main effect of drug dose: $F_{1.355,20.330}=$ 4.387, $p=0.039$, post-hoc: $p=0.047$; Table S7), and increased omissions for all tones (significant drug dose*tone interaction: $F_{2.343,35.150}=4.739, p=0.011$, main effect of drug dose: $F_{2,30}=$ $24.257, p<0.001$, post-hoc: $p s<0.001$; Table S7). The lower dose also caused response latencies to increase (post-hoc: $p<0.001$; Table S7), accuracy to increase (main effect of drug dose: $F_{1.605,24.069}=8.558, p=0.003$, post-hoc: $p=0.002$; Table S7), and omissions to increase for all tones (post-hoc: $p s \leq 0.019$; Table S7).

Ketamine. In the rats who had undergone mPFC cannulation surgery, ketamine $(1.0 \mathrm{mg} / \mathrm{kg})$ caused a positive change in $\mathrm{CBI}$ (paired samples t-test: $p=0.033$; Fig. $2 \mathrm{c}$ ), as has been seen previously [24]. Ketamine did not alter any other behavioural measures (Table S7).

Lanicemine. None of the doses of lanicemine tested caused a change in CBI (Fig. 2d). This drug also had no effect on any other behavioural measures (Table S7).
Memantine. Memantine did not cause any change in $\mathrm{CBI}$ at the doses tested (Fig. 2e). There was also no effect on other behavioural measures (Table S7).

MK-801. MK-801 did not change CBI (Fig. 2f). The highest dose of MK-801 tested $(0.03 \mathrm{mg} / \mathrm{kg})$ decreased response latencies (main effect of drug dose: $F_{2,30}=3.843, p=0.033$; Table S7). There was no effect on accuracy for the reference tones, percentage omissions or premature responding.

High-dose ketamine. In experiment $2(25 \mathrm{mg} / \mathrm{kg}$ ketamine) one rat was excluded for failure to complete sufficient trials. In experiments 1 and 2 , ketamine $(10 \mathrm{mg} / \mathrm{kg}$ and $25 \mathrm{mg} / \mathrm{kg}$ respectively) did not change $\mathrm{CBI}$ (Fig. 3a). In both experiments these higher doses did alter all other behavioural measures. There was an increase in response latency across all three tones for both $10 \mathrm{mg} / \mathrm{kg}$ (drug dose*tone interaction: $F_{2,30}=7.323, p=0.003$, post-hoc: $p s<0.001$ for all tones; Fig. $3 c$ ), and $25 \mathrm{mg} / \mathrm{kg}$ ketamine (drug dose*tone interaction: $F_{2,28}=4.686, p=0.018$, post-hoc: ps $\leq 0.002$ for all tones; Fig. 3c). Both doses decreased premature responses (paired samples t-tests: $10 \mathrm{mg} / \mathrm{kg}-p=$ $0.005,25 \mathrm{mg} / \mathrm{kg}-p=0.006$; Fig. 3e). Ketamine also improved accuracy in experiment $1(10 \mathrm{mg} / \mathrm{kg}$ : main effect of drug dose: $F_{1,15}=8.774, p=0.010$; Fig. $\left.3 \mathrm{~b}\right)$ and for the low reward tone in experiment 2 ( $25 \mathrm{mg} / \mathrm{kg}$ : drug dose*tone interaction: $F_{1,14}=5.513$, $p=0.034$, post-hoc: $p=0.033$; Fig. $3 \mathrm{~b}$ ). In both experiments, there was an increase in omissions for all three tones (experiment 1, 10 $\mathrm{mg} / \mathrm{kg}$ : drug dose*tone interaction: $F_{1.401,21.021}=5.662, p=0.018$, post-hoc: high reward tone $-p=0.015$, midpoint tone: $p=0.003$, low reward tone: $p=0.010$; experiment $2,25 \mathrm{mg} / \mathrm{kg}$ : drug dose*tone interaction: $F_{1.368,19.150}=11.964, p=0.001$, post-hoc: 
high reward tone $-p=0.003$, midpoint tone $-p<0.001$, low reward tone $-p=0.001$; Fig. $3 \mathrm{~d}$ ).

Low dose PCP. Doses of PCP $(0.03,0.1,0.3 \mathrm{mg} / \mathrm{kg})$ that were lower than those previously tested [24] did not cause any change in CBI (Fig. 2g). There was also no effect on any other behavioural measures (Table S7).

Analysis of performance split over session. In addition to the analyses above we also compared performance for the first and last 20 probe trials in order to check whether animals' performance changed within a session during these randomly reinforced trials. Analysis of the data for doses of ketamine $(1.0 \mathrm{mg} / \mathrm{kg})$, CP101606 $(6.0 \mathrm{mg} / \mathrm{kg})$ and scopolamine $(0.1 \mathrm{mg} / \mathrm{kg})$ which change $C B I$ did not find any evidence of differences across the session between vehicle or drug treatments based on this analysis (see Fig. S3).

\section{Study 2: mPFC infusions of drugs shown to cause positive judgement biases}

Two rats were excluded in cohort 3: one rat did not meet accuracy criteria for any probe (or baseline) session following the second drug infusion; and after the end of testing another animal was found to have an incorrect cannula placement. Therefore, both were excluded retrospectively from the entire study. Compared to pre-surgery performance, the $\mathrm{CBI}$ of rats became more negative after surgery, and this was stable across testing over 3 weeks (main effect of week: $F_{3,42}=6.335, p=$ 0.001 , post-hoc: $p s \leq 0.011$; Fig. $4 a$ ). There were no differences in response latencies, premature responses, accuracies for reference tones or omissions before compared to after surgery (Table S7). The change in $\mathrm{CBI}$ occurred before infusions and seemed to be a response to the surgical intervention potentially causing a more negative affective state. We found no evidence of tissue damage in the area surrounding the cannula postmortem, so it is unlikely that this was a result of trauma. We think it is not surprising that undergoing surgery and having to adapt to intracerebral cannula could cause a permanent negative change in affect. It is exactly this sort of affective state change that judgement bias assays have been developed to detect (for example see Bethell [38], and Baciadonna \& McElligott [39] for reviews summarising how judgement bias tasks can be used as measure of animal welfare).

In the first infusion experiment, ketamine $(1.0 \mu \mathrm{g} / \mu \mathrm{l})$, muscimol $(0.1 \mu \mathrm{g} / \mu \mathrm{l})$ and scopolamine $(0.1 \mu \mathrm{g} / \mu \mathrm{l})$ all induced positive biases (main effect of drug dose: $F_{3,36}=7.241, p=0.001$; post-hoc: ketamine $-p=0.012$, muscimol $-p=0.001$, scopolamine $-p=$ 0.032 Fig. 4c). The effect of PFC infusion of ketamine or scopolamine was specific to $\mathrm{CBI}$, as these drugs had no effect on other behavioural measures (Fig. 4d-g), unlike muscimol infusions which caused changes to all other behavioural measures. There was an increase in response latency (drug dose*tone interaction: $F_{6,72}=4.181, p=0.001$ ) for the high reward (post-hoc: $p<0.001)$ and midpoint tone $(p=0.028$; Fig. $4 \mathrm{e})$, and a large increase in premature responses to over $100 \%$ (main effect of drug dose: $F_{1.151,13.809}=33.784, p<0.001$, post-hoc: $p<0.001$; Fig. $4 \mathrm{~g}$ ). Muscimol also caused accuracy to decrease (main effect of drug dose: $F_{1.181,14.172}=43.775, p<0.001$, post-hoc: $p \leq 0.001$; Fig. $4 d$ ). For the low reward tone, this reduction was so great that rats were no longer performing any better than chance (one-sample t-test against a test value of 50\%: $p=0.197$; Fig. 4d). Omissions increased following muscimol infusion (main effect of drug dose: $F_{1.338,16.057}=10.418, p=0.003$, post-hoc: $p=0.007$; Fig. $4 \mathrm{f}$ ).

In the experiments testing the effect of CP-101,606 mPFC infusion, in experiment 1 the lower dose $(1.0 \mu \mathrm{g} / \mu \mathrm{l})$ did not alter $\mathrm{CBI}$ (Fig. 5a), but in experiment 2, the higher dose $(3.0 \mu \mathrm{g} / \mu \mathrm{l})$ induced a positive bias (paired samples $t$ test: $p=0.043$; Fig. $5 a$ ). In experiment $1, C P-101,606(1.0 \mu \mathrm{g} / \mu \mathrm{l})$ caused an increase in response latency (main effect of drug dose: $F_{1,12}=5.064, p=$ 0.044; Fig. 5c) but had no other behavioural effects (Fig. 5b, d, e). In experiment 2, 3.0 $\mu \mathrm{g} / \mu \mathrm{l} C \mathrm{CP}-101,606 \mathrm{did}$ not have any effects on other behavioural measures (Fig. 5b-e).

\section{DISCUSSION}

As previously shown [24], low dose ketamine $(1.0 \mathrm{mg} / \mathrm{kg})$ had a specific effect on decision-making biases, inducing a positive change in $\mathrm{CBI}$ following acute administration. This effect of ketamine was dose dependent, with higher doses having general effects on task performance without changing CBI. The effects of ketamine were recapitulated to some extent by the GluN2B antagonist, CP-101,606 and muscarinic antagonist, scopolamine, but both also had more general effects on other behavioural measures following systemic administration. All three treatments have previously been reported to have RADD effects in clinical trials $[3,28,29]$, whilst the other NMDA antagonists tested here did not $[5,25-27]$, and these also failed to induce a change in bias. The mPFC infusions suggest that this brain region is central to the effects of ketamine, scopolamine and CP-101,606. Interestingly, mPFC infusions more specifically altered bias, suggesting other brain regions may contribute to the systemic effects on other behavioural measures. The importance of the MPFC in modulating RAAD effects in neuropsychological tasks is consistent with previous findings in our learning and memory bias assay, the affective bias test [33]. Inactivation of the MPFC with muscimol did positively change bias but animals also exhibited large changes in other behavioural measures. This suggests that the RAADs can modulate activity in this brain region in a more specific way than muscimol, which results in a relatively specific effect on biases in decision-making.

For lanicemine and memantine, the lack of any behavioural effects means there is a possibility that the doses tested were too low. For both treatments the range of doses tested covers the doses that are equivalent to those used humans in clinical trials (lanicemine: 50, $100 \mathrm{mg}$ [25], equivalent to approximately 0.75 , $1.5 \mathrm{mg} / \mathrm{kg}$; memantine: $5-20 \mathrm{mg}^{5}$, equivalent to approximately $0.07-0.3 \mathrm{mg} / \mathrm{kg}$ ), paralleling our effective dose of ketamine $(1.0 \mathrm{mg} / \mathrm{kg}$, similar to the $0.5 \mathrm{mg} / \mathrm{kg}$ dose used by Zarate et al. [3]). Although higher doses may yield behavioural effects, these are likely to be due to much higher levels of receptor occupancy than those relevant to the antidepressant effects and may also arise from non-specific actions at other receptors. When testing lower doses of PCP (another NMDA receptor antagonist not known to show RAAD) than previously used [24], we also failed to see any change in CBI. Conversely, when we tested higher doses of ketamine than those we had previously [24], doses that are often used to demonstrate antidepressant effects in other preclinical models used to study depression such as the forced swim test (FST) [40], we failed to see any change in bias, instead only seeing non-specific changes in other behavioural measures. The behavioural profile seen with these higher doses of ketamine (increased response latency and omissions and decreased premature responding) suggests that these doses may be causing locomotor depression or reducing motivation to respond. Higher doses of ketamine have not been found to have antidepressant effects in clinical trials and these data also suggest that rodent studies using these higher doses may not be looking at specific effects. It may be that the lower $1.0 \mathrm{mg} / \mathrm{kg}$ dose of ketamine can specifically alter decision-making biases because they target a specific population and hence modulate a specific circuit. Some studies have suggested that ketamine may act via disinhibition of GABAergic interneurons leading to a glutamate burst which then activates prefrontal glutamate neurons [41]. Overall, the results from systemic administration of different NMDA receptor antagonists lends support to our interpretation that this reward-based judgement bias task can specifically dissociate between drugs that 
A

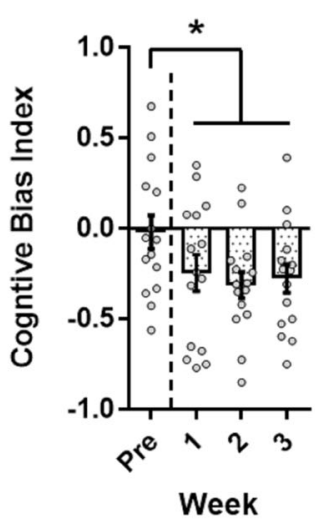

C

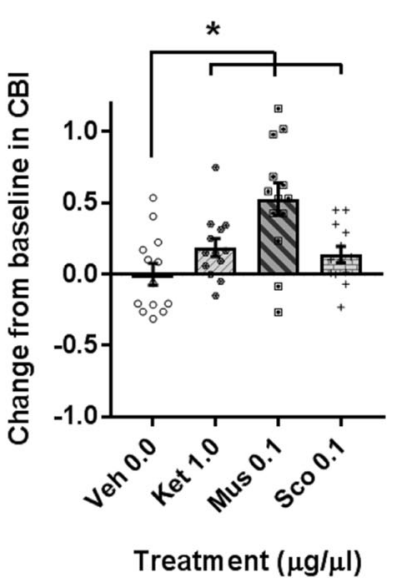

B

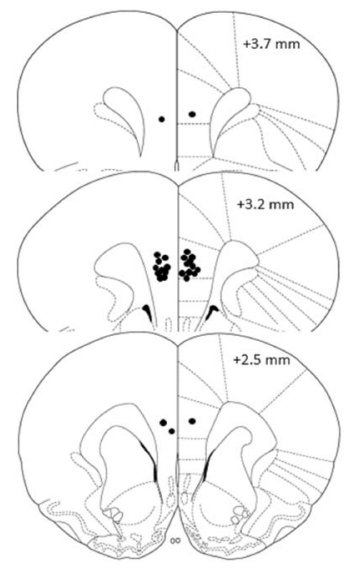

D

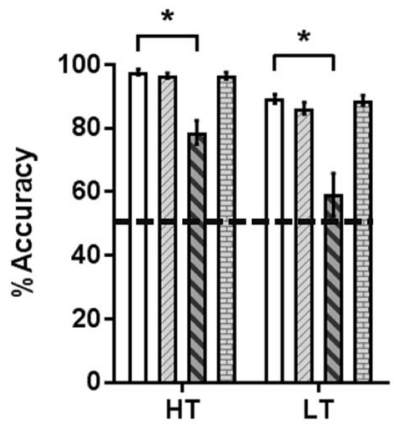

Veh $0.0 \mu \mathrm{g} / \mu \mathrm{l}$ Mus $0.1 \mu \mathrm{g} / \mu \mathrm{l}$
Ket $1.0 \mu \mathrm{g} / \mu \mathrm{l} \square \mathrm{Sco} 0.1 \mu \mathrm{g} / \mu \mathrm{l}$
E

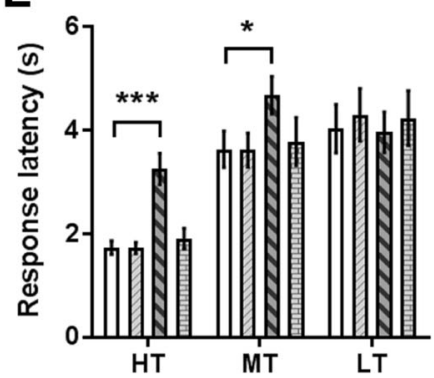

$\mathbf{F}$
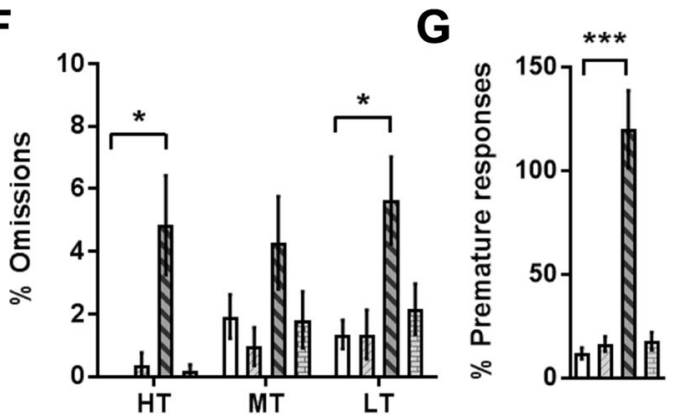

Fig. 4 Data from mPFC cannulated rats on the judgement bias task. Probe tests with no experimental manipulation were conducted before and after mPFC cannulation surgery to ensure that the surgery itself did not effect performance in the judgement bias task. a Cognitive bias index became more negative in the probe tests conducted after surgery. b The location of the injector placement was confirmed postmortem and black dots represent the location of the cannula tip as assessed from Cresyl violet-stained brain sections. Coronal sections are $+3.7 \mathrm{~mm}$ to $+2.5 \mathrm{~mm}$ relative to bregma (Paxinos and Watson, 1998). c-g In the first infusion experiment, ketamine (Ket; $1.0 \mu \mathrm{g} / \mu \mathrm{l}) \mathrm{muscimol}$ (Mus; $0.1 \mu \mathrm{g} / \mu \mathrm{l}$ ), scopolamine (Sco; $0.1 \mu \mathrm{g} / \mu \mathrm{l}$ ) or vehicle (Veh; $0.0 \mu \mathrm{g} / \mu \mathrm{l} ; n=13$ ), were administered by intracerebral infusion into the mPFC to measure the effect on judgement bias. c Ketamine, muscimol and scopolamine all caused a positive change in cognitive bias index (CBI) for the midpoint tone. d Muscimol decreased accuracy for both reference tones. e Muscimol increased response latencies for the high and midpoint tones. f For the high and low tones, muscimol increased omissions. g Muscimol also increased premature responding. Data represent mean \pm SEM (panels $\mathbf{a}, \mathbf{c}-\mathbf{g}$ ) with individual data points overlaid for each rat (panel $\mathbf{a}, \mathbf{c})$. Black dashed line (panel $\mathbf{f}$ ) represents $50 \%$ accuracy depicting performance at chance. 5 min pre-treatment. ${ }^{* *} p<0.001,{ }^{*} p<0.05$. HT: high reward tone; MT: midpoint tone; LT: low reward tone.

do show RAAD, and those that do not, despite them having similar pharmacology.

The difference in specificity on behavioural effects, whereby ketamine $(1.0 \mathrm{mg} / \mathrm{kg})$ only positively changes decision-making bias, but both CP-101,606 and scopolamine have other nonspecific effects, suggests that $1.0 \mathrm{mg} / \mathrm{kg}$ ketamine is able to relatively selectively modulate affective bias. The changes in response latencies, omissions and premature responses caused by CP-101,606 and scopolamine suggest that these drugs may also be having effects on other cognitive processes, such as motivation. However, the direction of changes for these drugs are in opposite directions (decreases in response latency and omissions for CP-101,606 but increases in these for scopolamine) despite them both causing positive changes in CBI. This, combined with the lack of change in accuracy for the reference tones, suggest that these non-specific effects cannot fully explain the change in decision-making bias.

The neurobiology underlying the relative specificity of ketamine, CP-101,606 and scopolamine in being able to immediately alter decision-making bias, in contrast to the other NMDA receptor 
A

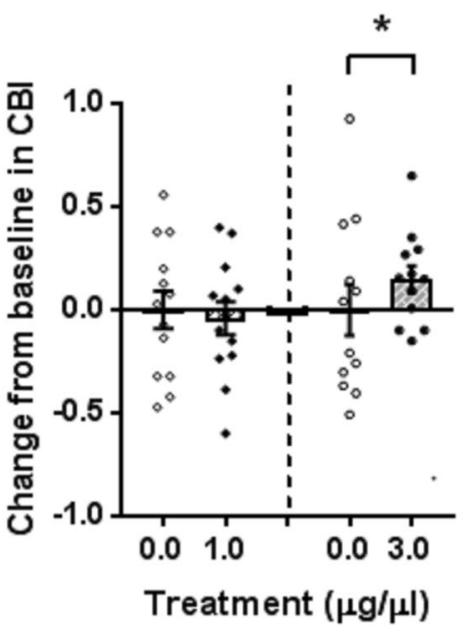

B

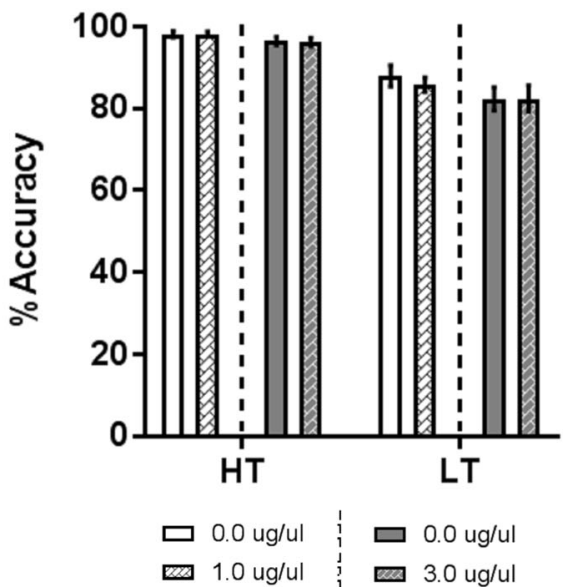

C

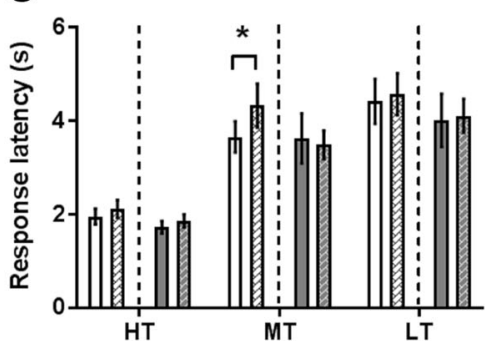

D

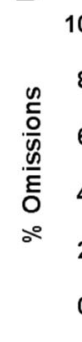

$\mathbf{E}$

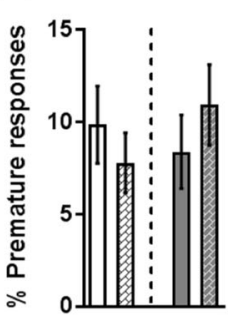

Fig. 5 Behavioural data from the judgement bias task following mPFC infusions of CP-101,606. CP-101,606 (Expt 1:00.0, 1.0 $\mu$ g/ $\mu$, $n=13$; Expt 2: $0.0,3.0 \mu \mathrm{g} / \mu \mathrm{l}, n=12$ ) was administered by intracerebral infusion in the mPFC to measure the effect on judgement bias. a The higher dose of CP-101,606 $(3.0 \mu \mathrm{g} / \mu \mathrm{l})$ caused a positive change from baseline in CBI. b Accuracy was not altered by either dose of CP-101,606. c In experiment 1, CP-101,606 $(1.0 \mu \mathrm{g} / \mu \mathrm{l})$ increased response latency for the midpoint tone. $\mathbf{d}$, e There was no effect of either dose on omissions or premature responding, ${ }^{*} p<0.05$. Data represent mean \pm SEM (panels $\mathbf{b}-\mathbf{e}$ ) with individual data points overlaid for each rat (panel a). Dashed lines indicate separate, counterbalanced experiments. 5 min pre-treatment. HT: high reward tone, MT: midpoint tone, LT: low reward tone.

antagonists tested that have not shown these effects, are likely to be due to differences in their mechanisms of action. Our findings add weight to the strong body of evidence suggesting that NMDA receptor antagonism is important for short-term, RAAD effects of these drugs [42], but suggests that specific modulation of either a specific subtype of the receptor or a sub-population of neurons may be involved. CP-101,606 is selective for the GluN2B NMDA receptor subunit, whilst it has been shown that scopolamine, and more recently ketamine, cause a glutamate burst via blockade of NMDA receptors specifically on GABA interneurons that leads to increased mechanistic target of rapamycin complex 1 signalling, brain-derived neurotrophic factor release and synaptic changes in the PFC $[41,43-45]$. Further studies would be required to test whether these mechanisms also drive these drugs effects on affective bias.

The infusion studies localise the site of action of this rapid change in decision-making bias to the MPFC, corresponding with brain imaging studies in humans that have also shown ketaminedependent changes in prefrontal glutamatergic neurotransmission $[31,32]$. This also matches with previous rodent studies, where using the affective bias test, it has been shown that whilst ketamine does not induce positive biases in learning, it can remediate previously acquired negative biases, an effect which also localises to the mPFC [33]. For CP-101,606 and scopolamine, unlike when given systemically, intracerebral mPFC infusion did not cause any non-specific behavioural changes on the task. This could suggest that these non-specific effects are driven by offtarget effects of drug binding in other brain areas, or in the case of scopolamine, the periphery. The localisation of the positive modulation of decision-making caused by these drugs to the
mPFC provides further support for the hypothesis that this might be mediated through burst firing in the PFC, an effect that has recently been shown to cause the activation of downstream pathways thought to be important in the RAAD effects of both ketamine and scopolamine [41, 43-45].

Interestingly, both $\mathrm{GABA}_{\mathrm{A}}$ receptor agonism (musciol infusion), and NMDA receptor antagonism (ketamine infusion) in the $\mathrm{mPFC}$ caused the same qualitative, but not quantitative behavioural change in judgement bias (a positive shift but of different magnitudes), mirroring findings seen previously with intrainfralimbic infusions of muscimol and (R)-CPP on the five choice serial reaction time task, where both drugs increased impulsive responding but by different amounts [46]. It has been suggested that the functional effects of NMDA receptor antagonism may be due to excess extracellular glutamate [47, 48]. However, the pronounced, non-specific behavioural effects on other measures seen following muscimol infusion suggests that mechanism of action of the other infusion drugs is more refined than global inhibition of neurotransmission in the mPFC. Previous work in humans and rodents has shown that subcortical and limbic brain regions, such as the amygdala, are important in the neurocircuitry of MDD / depression-related behaviour [49-51], and a recent study suggests that ketamine may play a critical role in restoring dysfunctional connectivity in these circuits [32]. Furthermore, in rodents, a recent study found that optogenetic activation of pyramidal mPFC neurons containing dopamine receptor D1 caused RAAD-like responses in the forced swim test, and that blockade of these receptors prevented the RAAD effects of ketamine [52]. In order to further our understanding of this 
mechanism, it will be important to investigate the effects of these drugs on different neuronal subtypes within the mPFC, as well as investigating the wider circuitry that is altered by these drugs.

Final conclusions

This study adds to the evidence that the neuropsychological effects of ketamine are potentially important in its RAAD effects in patients with MDD, and that these effects in altering affective biases, both in decision-making as demonstrated here, as well as in learning and memory occur at time points $(1 \mathrm{~h})$ before major plastic changes arise. It will be important to investigate the neurobiological effects of not just the immediate, RAAD of ketamine, but also the sustained effects by examining how affective biases are altered at longer time points. Furthermore, investigation of the wider circuits involved in this RAAD efficacy will be crucial in revealing the mechanism underlying these actions, which will be important for the development of novel therapeutics. Ketamine (at $1.0 \mathrm{mg} / \mathrm{kg}$ ) seems to have very specific effects on affective bias, which we can capitalise on to better understand the circuits that contribute to these modulations of affective biases that are potentially very important in the cause, perpetuation and treatment of MDD. More detailed circuit analyses are needed including undertaking studies in other brain regions to determine whether ketamine's effects are specific to the mPFC.

\section{FUNDING AND DISCLOSURE}

This research was funded by an Industrial Partnership Award awarded by BBSRC in collaboration with Boehringer Ingelheim (Grant no: BB/N015762/1) and carried out with intellectual support from Boehringer Ingelheim. ESJR has current or previously obtained research grant funding through $\mathrm{PhD}$ studentships, collaborative grants and contract research from Boehringer Ingelheim, Compass Pathways, Eli Lilly, MSD, Pfizer and SmallPharma. The authors declare no conflict of interest.

\section{AUTHOR CONTRIBUTIONS}

C.A.H. performed the research, analysed data, wrote and edited the paper. J.M.B. performed research and analysed data. R.A. and B.H. designed the research and edited the paper. E.S.J.R. designed the research and wrote and edited the paper.

\section{ADDITIONAL INFORMATION}

Supplementary Information accompanies this paper at (https://doi.org/10.1038/ s41386-020-00797-3)

Publisher's note Springer Nature remains neutral with regard to jurisdictional claims in published maps and institutional affiliations.

\section{REFERENCES}

1. World Health Organization. Depression fact sheet. 2018. https://www.who.int/ news-room/fact-sheets/detail/depression. Accessed 5 Nov 2019.

2. Anderson IM, Nutt DJ, Deakin JFW. Evidence-based guidelines for treating depressive disorders with antidepressants: a revision of the 1993 British Association for Psychopharmacology guidelines. J Psychopharmacol. 2000;14:3-20.

3. Zarate CA,Jr, Singh JB, Carlson PJ, Brutsche NE, Ameli R, Luckenbaugh DA. et al. A randomized trial of an $\mathrm{N}$-methyl-D-aspartate antagonist in treatment-resistant major depression. Arch Gen Psychiatry. 2006;63:856-64.

4. Berman RM, Cappiello A, Anand A, Oren DA, Heninger GR, Charney DS. et al. Antidepressant effects of ketamine in depressed patients. Biol Psychiatry. 2000;47:351-4.

5. Zarate CA,Jr, Singh JB, Quiroz JA, De Jesus G, Denicoff KK, Luckenbaugh DA. et al. A double-blind, placebo-controlled study of memantine in the treatment of major depression. Am J Psychiatry. 2006;163:153-5.

6. DiazGranados N, Ibrahim LA, Brutsche NE, Ameli R, Henter ID, Luckenbaugh DA. et al. Rapid resolution of suicidal ideation after a single infusion of an $\mathrm{N}$-methylD-aspartate antagonist in patients with treatment-resistant major depressive disorder. J Clin Psychiatry. 2010;71:1605-11.
7. Lapidus KA, Levitch CF, Perez AM, Brallier JW, Parides MK, Soleimani L. et al. A randomized controlled trial of intranasal ketamine in major depressive disorder. Biol Psychiatry. 2014;76:970-6.

8. Price RB, losifescu DV, Murrough JW, Chang LC, Al Jurdi RK, lqbal SZ. et al. Effects of ketamine on explicit and implicit suicidal cognition: a randomized controlled trial in treatment-resistant depression. Depression Anxiety. 2014;31:335-43.

9. Mathews A, MacLeod C. Cognitive vulnerability to emotional disorders. Annu Rev Clin Psychol. 2005;1:167-95.

10. Clark L, Chamberlain SR, Sahakian BJ. Neurocognitive mechanisms in depression: implications for treatment. Annu Rev Neurosci. 2009;32:57-74.

11. Gotlib IH, Joormann J. Cognition and depression: current status and future directions. Annu Rev Clin Psychol. 2010;6:285-312.

12. Harmer CJ, Bhagwagar Z, Perrett DI, Vollm BA, Cowen PJ, Goodwin GM. Acute SSRI administration affects the processing of social cues in healthy volunteers. Neuropsychopharmacology. 2003;28:148-52.

13. Harmer CJ, Shelley NC, Cowen PJ, Goodwin GM. Increased positive versus negative affective perception and memory in healthy volunteers following selective serotonin and norepinephrine reuptake inhibition. Am J Psychiatry. 2004;161:1256-63.

14. Harmer CJ, de Bodinat C, Dawson GR, Dourish CT, Waldenmaier L, Adams S. et al. Agomelatine facilitates positive versus negative affective processing in healthy volunteer models. J Psychopharmacol (Oxf, Engl). 2011;25:1159-67.

15. Harmer CJ, O'Sullivan U, Favaron E, Massey-Chase R, Ayres R, Reinecke A. et al. Effect of acute antidepressant administration on negative affective bias in depressed patients. Am J Psychiatry. 2009;166:1178-84.

16. Stuart SA, Butler P, Munafo MR, Nutt DJ, Robinson ES. A translational rodent assay of affective biases in depression and antidepressant therapy. Neuropsychopharmacology. 2013;38:1625-35.

17. Harding EJ, Paul ES, Mendl M. Animal behaviour: Cognitive bias and affective state. Nature. 2004;427:312-312.

18. Robinson E, Roiser J. Affective biases in humans and animals. In: Robbins TW, Sahakian BJ, editors. Translational neuropsychopharmacology. Current topics in behavioral neurosciences, Vol. 28. Cham: Springer; 2015.

19. Mendl M, Burman OHP, Paul ES. An integrative and functional framework for the study of animal emotion and mood. Proc R Soc B: Biol Sci. 2010;277:2895-904.

20. Roelofs $\mathrm{S}$, Boleij $\mathrm{H}$, Nordquist RE, van der Staay FJ. Making decisions under ambiguity: judgment bias tasks for assessing emotional state in animals. Frontiers Behav Neurosci. 2016;10:119.

21. Neville V, Nakagawa S, Zidar J, Paul ES, Lagisz M, Bateson M. et al. Pharmacological manipulations of judgement bias: a systematic review and meta-analysis. Neurosci Biobehav Rev. 2020;108:269-86.

22. Hales CA, Robinson ES, Houghton CJ. Diffusion modelling reveals the decision making processes underlying negative judgement bias in rats. PloS ONE. 2016;11: e0152592.

23. Parker RM, Paul ES, Burman OH, Browne WJ, Mendl M. Housing conditions affect rat responses to two types of ambiguity in a reward-reward discrimination cognitive bias task. Behav Brain Res. 2014;274:73-83.

24. Hales CA, Houghton CJ, Robinson ESJ. Behavioural and computational methods reveal differential effects for how delayed and rapid onset antidepressants effect decision making in rats. Eur Neuropsychopharmacol. 2017;27:1268-80.

25. Sanacora G, Johnson MR, Khan A, Atkinson SD, Riesenberg RR, Schronen JP. et al. Adjunctive lanicemine (AZD6765) in patients with major depressive disorder and history of inadequate response to antidepressants: a randomized, placebocontrolled study. Neuropsychopharmacology. 2017;42:844-53.

26. Smith EG, Deligiannidis KM, Ulbricht CM, Landolin CS, Patel JK, Rothschild AJ. Antidepressant augmentation using the $\mathrm{N}$-methyl-D-aspartate antagonist memantine: a randomized, double-blind, placebo-controlled trial. J Clin Psychiatry. 2013;74:966-73.

27. Ates-Alagoz Z, Adejare A. NMDA receptor antagonists for treatment of depression. Pharmaceuticals (Basel). 2013;6:480-99.

28. Preskorn SH, Baker B, Kolluri S, Menniti FS, Krams M, Landen JW. An innovative design to establish proof of concept of the antidepressant effects of the NR2B subunit selective N-methyl-D-aspartate antagonist, CP-101,606, in patients with treatmentrefractory major depressive disorder. J Clin Psychopharmacol. 2008;28:631-7.

29. Furey ML, Drevets WC. Antidepressant efficacy of the antimuscarinic drug scopolamine: a randomized, placebo-controlled clinical trial. Arch Gen Psychiatry. 2006;63:1121-9.

30. Browne CA, Lucki I. Antidepressant effects of ketamine: mechanisms underlying fast-acting novel antidepressants. Front Pharmacol. 2013;4:161.

31. Li CT, Chen MH, Lin WC, Hong CJ, Yang BH, Liu RS. et al. The effects of low-dose ketamine on the prefrontal cortex and amygdala in treatment-resistant depression: a randomized controlled study. Hum Brain Mapp. 2016;37:1080-90.

32. Abdallah CG, De Feyter HM, Averill LA, Jiang L, Averill CL, Chowdhury GMI. et al The effects of ketamine on prefrontal glutamate neurotransmission in healthy and depressed subjects. Neuropsychopharmacology. 2018;43:2154-60. 
Role of the medial prefrontal cortex in the effects of rapid acting...

CA Hales et al.

2288

33. Stuart SA, Butler $P$, Munafo MR, Nutt DJ, Robinson ES. Distinct neuropsychological mechanisms may explain delayed- versus rapid-onset antidepressant efficacy. Neuropsychopharmacology. 2015;40:2165-74.

34. Stuart SA, Robinson ESJ. Reducing the stress of drug administration: implications for the 3Rs. Sci Rep. 2015;5:14288.

35. Duman RS. Ketamine and rapid-acting antidepressants: a new era in the battle against depression and suicide. F1000Research 2018;7:F1000 Faculty Rev-659.

36. Benn A, Robinson ES. Investigating glutamatergic mechanism in attention and impulse control using rats in a modified 5-choice serial reaction time task. PloS ONE. 2014;9:e115374.

37. Paxinos G, Watson C. The rat brain-in stereotaxic coordinates. San Diego, CA: Academic Press; 1998.

38. Bethell EJ. A "how-to" guide for designing judgment bias studies to assess captive animal welfare. J Appl Anim Welf Sci. 2015;18:S18-S42.

39. Baciadonna L, McElligott AG. The use of judgement bias to assess welfare in farm livestock. Anim Welf. 2015;24:81-91.

40. Polis AJ, Fitzgerald PJ, Hale PJ, Watson BO. Rodent ketamine depression-related research: Finding patterns in a literature of variability. Behav Brain Res. 2019;376:112153.

41. Gerhard DM, Pothula S, Liu RJ, Wu M, Li XY, Girgenti MJ et al. GABA interneurons are the cellular trigger for ketamine's rapid antidepressant actions. J Clin Invest. 2020;130:1336-1349.

42. Drewniany E, Han J, Hancock C, Jones RL, Lim J, Nemat Gorgani N. et al. Rapid-onset antidepressant action of ketamine: potential revolution in understanding and future pharmacologic treatment of depression. J Clin Pharm Ther. 2015;40:125-30.

43. Li N, Lee B, Liu RJ, Banasr M, Dwyer JM, Iwata M. et al. mTOR-dependent synapse formation underlies the rapid antidepressant effects of NMDA antagonists. Science. 2010;329:959-64.
44. Voleti B, Navarria A, Liu RJ, Banasr M, Li N, Terwilliger R. et al. Scopolamine rapidly increases mammalian target of rapamycin complex 1 signaling, synaptogenesis, and antidepressant behavioral responses. Biol Psychiatry. 2013;74:742-9.

45. Wohleb ES, Wu M, Gerhard DM, Taylor SR, Picciotto MR, Alreja M. et al. GABA interneurons mediate the rapid antidepressant-like effects of scopolamine. J Clin Invest. 2016;126:2482-94.

46. Murphy ER, Fernando ABP, Urcelay GP, Robinson ESJ, Mar AC, Theobald DEH. et al. Impulsive behaviour induced by both NMDA receptor antagonism and GABAA receptor activation in rat ventromedial prefrontal cortex. Psychopharmacology. 2012;219:401-10.

47. Ceglia I, Carli M, Baviera M, Renoldi G, Calcagno E, Invernizzi RW. The 5-HT receptor antagonist $\mathrm{M} 100,907$ prevents extracellular glutamate rising in response to NMDA receptor blockade in the mPFC. J Neurochem. 2004;91:189-99.

48. Moghaddam B, Adams B, Verma A, Daly D. Activation of glutamatergic neurotransmission by ketamine: a novel step in the pathway from NMDA receptor blockade to dopaminergic and cognitive disruptions associated with the prefrontal cortex. J Neurosci. 1997;17:2921-7.

49. Eshel N, Roiser JP. Reward and punishment processing in depression. Biol Psychiatry. 2010;68:118-24.

50. Murrough JW, lacoviello B, Neumeister A, Charney DS, losifescu DV. Cognitive dysfunction in depression: neurocircuitry and new therapeutic strategies. Neurobiol Learn Mem. 2011;96:553-63.

51. Biselli T, Lange S, Sablottny L, Steffen J, Walther A. Optogenetic and chemogenetic insights into the neurocircuitry of depression-like behaviour: a systematic review. Eur J Neurosci. https://doi.org/10.1111/ejn.14603. [Epub ahead of print].

52. Hare BD, Shinohara R, Liu RJ, Pothula S, DiLeone RJ, Duman RS. Optogenetic stimulation of medial prefrontal cortex Drd1 neurons produces rapid and longlasting antidepressant effects. Nat Commun. 2019;10:223. 